\title{
BMJ Open More aware, more protected: a cross- sectional study on road safety skills predicting the use of passive safety elements among Spanish teenagers
}

\author{
Sergio Useche (D , ${ }^{1}$ Francisco Alonso, ${ }^{1}$ Luis Montoro, ${ }^{2}$ Leandro Garrigós ${ }^{3}$
}

To cite: Useche S, Alonso F, Montoro L, et al. More aware, more protected: a crosssectional study on road safety skills predicting the use of passive safety elements among Spanish teenagers. BMJ Open 2019;9:e035007. doi:10.1136/ bmjopen-2019-035007

- Prepublication history and additional material for this paper are available online. To view these files, please visit the journal online (http://dx.doi. org/10.1136/bmjopen-2019035007).

Received 16 October 2019 Revised 21 0ctober 2019 Accepted 24 October 2019

Check for updates

(c) Author(s) (or their employer(s)) 2019. Re-use permitted under CC BY-NC. No commercial re-use. See rights and permissions. Published by BMJ.

${ }^{1}$ DATS (Development and Advising in Traffic Safety) Research Group - INTRAS (Research Institute on Traffic and Road Safety), Universitat de Valencia, Valencia, Valencian Community, Spain

${ }^{2}$ FACTHUM.Lab (Human Factor and Road Safety) Research Group - INTRAS (Research Institute on Traffic and Road Safety), University of Valencia, Valencia, Valencian Community, Spain

${ }^{3}$ Generalitat Valenciana

(Government of the Valencian Community), Valencia, Valencian Community, Spain

Correspondence to

Dr. Sergio Useche;

sergio.useche@uv.es

\section{ABSTRACT}

Objective This study had two objectives: first, to test the effects of sociodemographic variables, and the effects of three key road safety skills (knowledge-risk perceptionattitudes) on the use of passive safety elements (PSEs) among teenagers; and second, to assess the differential impact of the study variables on PSEs use from a genderbased perspective.

Setting and participants This cross-sectional study was framed in the paradigm of primary care, and it involved students from several educational centres in Spain. A sample of 827 Spanish teenagers (52.4\% females and $47.6 \%$ males) with a mean age of $\mathrm{M}=14.4^{1-7}(12-19)$ years was used.

Results Through SEM modelling, we found that the use of PSEs is largely explained by psychosocial variables through the mediation of three road safety skills: risk perception $\left(\beta=0.103^{* \star \star}\right)$, rule knowledge $\left(\beta=0.095^{*}\right)$ and attitudes towards road safety $\left(\beta=0.186^{* \star *}\right)$. Furthermore, multigroup analyses showed that, although most variables explain the use of PSEs among teenagers in a similar way, key gender-based differences exist in this regard.

Conclusions Road safety skills have a significant effect on the use of PSEs among Spanish teenagers, and gender explains some differences in the mechanisms which predict them. Also, in the study we discuss the need for strengthening school-based interventions aimed at helping this vulnerable group of road users acquire and develop positive behavioural competences.

\section{INTRODUCTION}

Daily transportation is an essential process for most population segments, and this fact implies both benefits and risks for road users. ${ }^{89}$ To this date, the educational system can be considered a sphere closely related to the transport industry, since schooling typically implies the everyday commuting of children and teens to and from their educational centres, for which different means of transportation are used, some of them more proper and safer than others. ${ }^{810}$ This implies, of course, a large set of risk factors that affect the health and welfare of young people, and
Strengths and limitations of this study

- Enhancing the use of passive safety elements is known to decrease the injury risk in traffic.

- This study offers useful information on factors that strengthen the use of passive safety elements among adolescents.

- These evidence-based findings could be addressed in interventions and multisectoral strategies aimed at improving the road safety competences of young population.

- As a key limitation, findings of self-report-based studies are prone to be affected by common method bias. Although data collection and analysis were rigorously carried out, results should be carefully interpreted when generalising to other populations.

traffic crashes are, perhaps, the most relevant one from the perspective of public health. ${ }^{911}$

Passive safety elements or PSEs (also known as secondary safety elements in some countries) are the set of in-vehicle or wearable devices designed to minimise the physical injuries that can derive from a traffic crash. For instance, epidemiological studies have shown that in the USA, during the last few years, no more than $17 \%$ of fatally injured cyclists were using helmets at the moment of suffering cycling crashes and, globally, it is estimated that around $60 \%$ of deaths of cyclists are related to head injuries. ${ }^{12} 13$ However, other studies have shown that (1) cyclists aged 10-20 are the least likely to wear a helmet while riding, ${ }^{14}$ and that (2) in other regions, such as Europe, only $68 \%$ of cyclists consider that helmets should be mandatory and just $38 \%$ of them use it regularly. ${ }^{15}$

Regarding seat belts, a key PSE in the case of motor vehicles (although its ratio may vary between countries), the percentage of seat belt users fatally injured in traffic crashes is, in countries such as the USA, less than half in the case of both drivers (47\%) and passengers 
$(34 \%) .{ }^{8}$ Moreover, most deceased drivers and occupants of vehicles were not using the seat belt at the moment of the fatal crash. Furthermore, since a clear disparity in driver-versus-passenger belting is still evident, and different cultural, informational and law-related barriers may enhance a scarce use of other elements such as helmets, ${ }^{9-11}$ severe traffic injuries that could be prevented are still highly prevalent worldwide among different risk groups of road users: such is the case of adolescents. ${ }^{11} 1617$

\section{Passive safety in the school: making the road for children and adolescents}

Recent evidence points out that, in many countries, traffic crashes constitute the main cause of death among adolescents. ${ }^{8}$ However, although different strategies have been adopted during the last 50 years, up to this date the proper use of PSEs is not generalised, especially in countries with a weaker tradition of road safety education (RSE) and training. ${ }^{16} 18$ In the field of school-based transportation, many advances in the equipment of school vehicles with better passive safety systems/devices have been reported, ${ }^{919}$ but, despite this fact, traffic injury rates involving school students are still a considerably relevant issue in the field of road safety. Overall, it is evident that technically improving the instruments (ie, means of transportation) is not enough: it is necessary to develop the behavioural resources of individuals, in order to increase their likelihood of permanent and appropriate use of safety features. ${ }^{812}$

Recent studies have problematised the scarcity of both the frequency and the appropriateness in the use of PSEs among adolescents. For instance, in a school-based study conducted by Shults et $a l^{8}$ it was found that, in the case of the USA, only half of teenagers $(51 \%)$ use the seat belt as passengers. Even worse, this percentage seems to drop systematically to $42 \%$ among high-school students, ${ }^{9}$ implying their increased risk of suffering severe injuries in traffic crashes. In this regard, apart from accessibility, several studies have described the importance of the enforcement of perceptual, representational, attitudinal, motivational and cognitive factors from school-related and microsocial environments for students to acquire safe habits since the early stages of their lives. This is an effective strategy that can reduce the prevalence and outcomes of risky road behaviours. ${ }^{1212}$

\section{Relational factors influencing the use of PSEs: the role of parenting}

Since the relationship between parents and children has a great influence in many spheres of life, safety behaviours are also highly influenced by parental issues. ${ }^{34}$ It is known that observational learning and parental influence play a crucial role in the acquisition and development of safety habits. ${ }^{56}$ As evidence suggests that negative or risky attitudes/behaviours could be learnt from parents and translated into risky and problematic behaviours that may compromise safety outcomes of children and adolescents, ${ }^{67}$ we also know that observed positive behaviours could be transmitted from parents to children, and the strengthening of parenting skills could enhance safe behaviour. In other words, parent-children relationships may also contribute to the learning of individual and social skills in fields such as road safety. ${ }^{4}$ Also, several empirical experiences highlight parenting as a potential source of improvement for both healthy habits and road safety behaviours, including the frequent and proper use of PSEs. ${ }^{5} 712$

\section{Objectives and hypotheses}

The core objective of this study was to assess the effect of sociodemographic variables, as well as the effect of three key road safety skills, on the use of PSEs among Spanish teenagers. In this regard, and following the available theoretical and empirical background described in the introduction, we hypothesised that the use of PSEs would be higher if road users constantly received more information about road safety issues, observed safer road behaviours in their parents, possessed a better psychological health and higher road safety skills (risk perception, knowledge and positive attitudes). This theoretical-based framework is synthesised in figure 1.

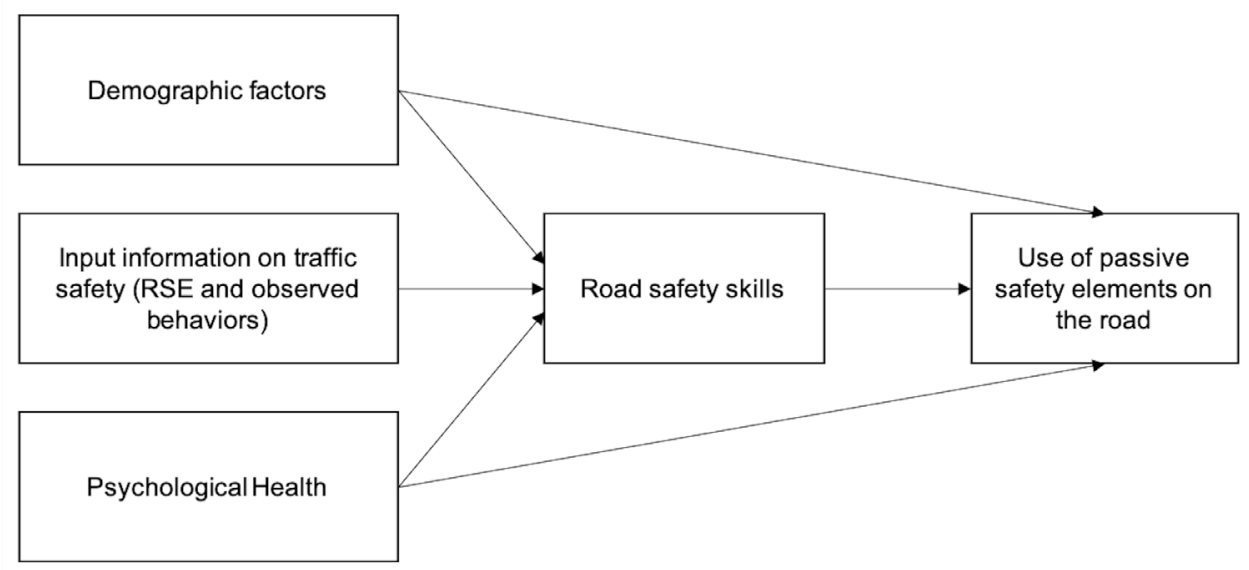

Figure 1 Hypothesised mediated path model for predicting the use of PSEs. Rectangles are the observed variables, and lines with arrows indicate the predicted paths. PSE, passive safety elements; RSE, road safety education. 
The second objective of the study was to evaluate the differential impact of these variables on the use of PSEs from a gender-based perspective (how similarly or differently do they work across genders?). The evidence has shown that, although several similarities exist between males and females in road safety-related issues, gender explains substantial differences in the decision-making within the behavioural context, such as the use of seat belts and helmets. Thus, it has been assumed that, if we apply the model to both genders keeping a similar structure, key differences between male and female teenagers will be observed in the variables affecting the use of PSEs.

\section{METHODS \\ Participants}

For this cross-sectional study, a sample of 827 Spanish teenagers, 433 females (52.4\%) and 394 males (47.6\%) was used. The participants were between 12 and 19 years old, and their mean age was $\mathrm{M}=14.39(\mathrm{SD}=1.60)$ years, with $\mathrm{M}=14.45(\mathrm{SD}=1.65)$ for females and $\mathrm{M}=14.33$ $(\mathrm{SD}=1.64)$ for males.

\section{Study design—setting}

In this school-based research, participants were invited to take part in the study through the mediation of their educational centres. As for the sampling technique, we employed a convenience (non-probabilistic) method, based on the accessibility to the study population and on their will to participate in the study.

Regarding the application of the questionnaire, it was completed in the classroom, with previous approval and assistance from the educational staff. Also, key factors such as the age range and the academic level of the study sample were taken into account for the selection of items and scales that composed the instrument. In the case of children and adolescents, some sources contained in the literature suggest the use of short forms synthetising the most relevant aspects of each variable, written in a clear and simple language,,$^{20}$ aspects that enhance an adequate understanding of the questions. Additionally: (a) we used instruments and items that had been previously tested in similar populations; (b) a researcher was always accessible to assist participants and (c) the anonymity of participation was continuously highlighted, emphasising the data protection principles and the fact that the information would only be used for research purposes, thus minimising biassed responses. We also kept in mind that most of participants were underaged. Thus, permissions signed by schools and associations of parents were obtained beforehand (including Informed Consent forms). All participants were initially informed about the importance of answering honestly to all the questions, as well as about the absence of right or wrong answers.

\section{Study variables and description of the questionnaire}

For this study, a paper-based questionnaire composed of four sections was designed, in order to measure each set of study variables (described below): the first section aimed at collecting demographic data (eg, age, gender and current academic year). In the second section, participants were asked about: (a) their exposure (received information) to RSE from different sources (eg, mass-media, advertising campaigns, school-based interventions and their teachers/ relatives $)$, through a 5 -item $(\alpha=0.73)$ Likert scale $(0=$ total disagreement; 4=total agreement) (example item: I remember seeing some campaigns on road safety); and (b) safe road behaviours observed in their parents, on a 5 -item $(\alpha=0.62)$ Likert scale $(0=$ never; $4=$ always $)$, in which they were asked about how often their parents performed three different key safe behaviours on the road: using seat belts, avoiding the cellphone while driving and speeding (example item: in the car, my parents always wear the seat belt'). Third, the questionnaire included the 12-item version of the General Health Questionnaire $^{21}(\alpha=0.72)$, which provides a single psychological health measure, and has been previously applied to similar populations in Spanish-speaking countries. ${ }^{22}{ }^{23}$ Finally, in the fourth section of the questionnaire we measured: (a) the use of PSEs, through a frequencybased Likert scale on the use of seat belts and helmets in cars, bicycles and motorcycles ( $0=$ never; $4=$ always), and (b) three core-skills related to RSE, through an 18-item questionnaire with two possible options for answer (yes/ no), in which each one of the three factors was composed of six items: knowledge of traffic rules $(\alpha=0.68)$, road risk perception $(\alpha=0.67)$ and positive attitudes towards road safety $(\alpha=0.73)$. The scale had already been adapted for the Spanish population in previous applications. ${ }^{4}$ The questionnaire (researcher form) is available as a online supplementary file of this paper.

\section{Patient and public involvement}

This study did not involve any clinical trial and/or patients.

\section{Data processing}

Basic descriptive analyses were performed to calculate scores for the different variables measured in the questionnaire. Pearson's correlational analyses were used to establish associations among the variables of the study, and once the basic parameters were tested, mean scores in the study variables were compared through analysis of variance (ANOVA). The explanatory association between age, exposure to RSE, psychological health and the statistical mediation of road safety skills in the use of PSEs was tested using SEM analysis with maximum likelihood estimations (MLE) and data imputation for missing data. Different measures were used for testing the model fit: minimum discrepancy (CMIN/DF; acceptable if <5.0), Normed Fit Index (NFI; ideal if $>0.90$ ), Comparative Fit Index (CFI; optimal if $>0.90$ ) and Root Mean Square Error of Approximation (RMSEA; better if $<0.08)$. The significance levels were $\mathrm{p}<0.05, \mathrm{p}<0.01$ and $\mathrm{p}<0.001$ (Model $A$ ). The statistical mediation specifies a chain of relations in which an antecedent variable affects a mediating variable, that in turn affects a dependent variable. ${ }^{24}$ Finally, the same model was tested for the second 
time, using a gender-based multigroup analysis (MGSEM with MLE) with differential criteria-significance levels of $\mathrm{p}<0.05, \mathrm{p}<0.01, \mathrm{p}<0.001$ (Model B). All statistical analyses were performed using IBM SPSS V.23.0, and AMOS V.24.0, specifically employed for structural and invariance analyses.

\section{RESULTS}

The descriptive statistics of the study are summarised in table 1. Apart from previously reported basic data on age and gender distribution, mean comparisons were carried out, in order to determine potential differences in the study variables between male and female subjects. The ANOVA revealed a significantly higher mean value for two road safety skills among female teenagers (ie, traffic rule knowledge and attitudes towards road safety) when compared with males, and a lower mean value for females in the indicator of psychological health. ${ }^{21}$ Correlational analysis allowed us to establish association measures between variables, all coherent to what had been theoretically hypothesised, and the use of PSEs was significantly associated with all the other study factors.

\section{Structural equation modelling}

With the aim of testing the background-based hypothesis about the effect of different factors on the use of PSEs, a structural equation model (SEM) was built. Considering that the initial model did not fit the data relatively well $\left(x^{2}(18)=200.97, \quad \mathrm{p}<0.001 ; \quad \mathrm{NFI}=0.700 ; \quad \mathrm{CFI}=0.701\right.$; RMSEA=0.161; CMIN/DF=11.329), some key modifications and constraints were performed. First of all, non-significant and very low paths between endogenousexogenous variables were set to zero, and modification indexes were applied to the model structure, always following the theoretical basis of the unconstrained model. Thus, a more parsimonious and reasonable model was obtained, with better fit coefficients and theoretical sense $\left(x^{2}(9)=18.598, \quad p<0.05 ; \quad \mathrm{NFI}=0.972\right.$; $\mathrm{CFI}=0.985 ; \mathrm{RMSEA}=0.036 ; \mathrm{CMIN} / \mathrm{DF}=2.066$ ). The model is presented in table 2 and figure 2 .

The model fit was established based on the cut-off criteria suggested by the specialised literature. ${ }^{25}$ The cutoff point of RMSEA is $<0.08$, and CFI/NFI values are ideal when $>0.9$. The standardised path coefficients of the SEM model suggest positive relations between risk perception $\left(\beta=0.103^{* * * *}\right)$, traffic rule knowledge $\left(\beta=0.095^{*}\right)$, positive attitudes towards road safety $\left(\beta=0.186^{* * *}\right)$ and the use of PSEs. A direct effect was spotted in the paths between the safe behaviours observed in parents $\left(\beta=0.420^{* * * *}\right)$, the psychological health indicator $\left(\beta=0.075^{* * *}\right)$ and the use of PSEs (dependent variable). No significant direct effects were found between the exposure to RSE, the age and the use of PSEs, the first two being fully mediated by road safety skills, as shown in table 2 and in the values next to solid lines in figure 2.

\section{Effect of gender on the use of PSEs: multigroup analysis}

Based on the theoretical assumptions presented in the introduction, the effect of gender on the use of PSEs

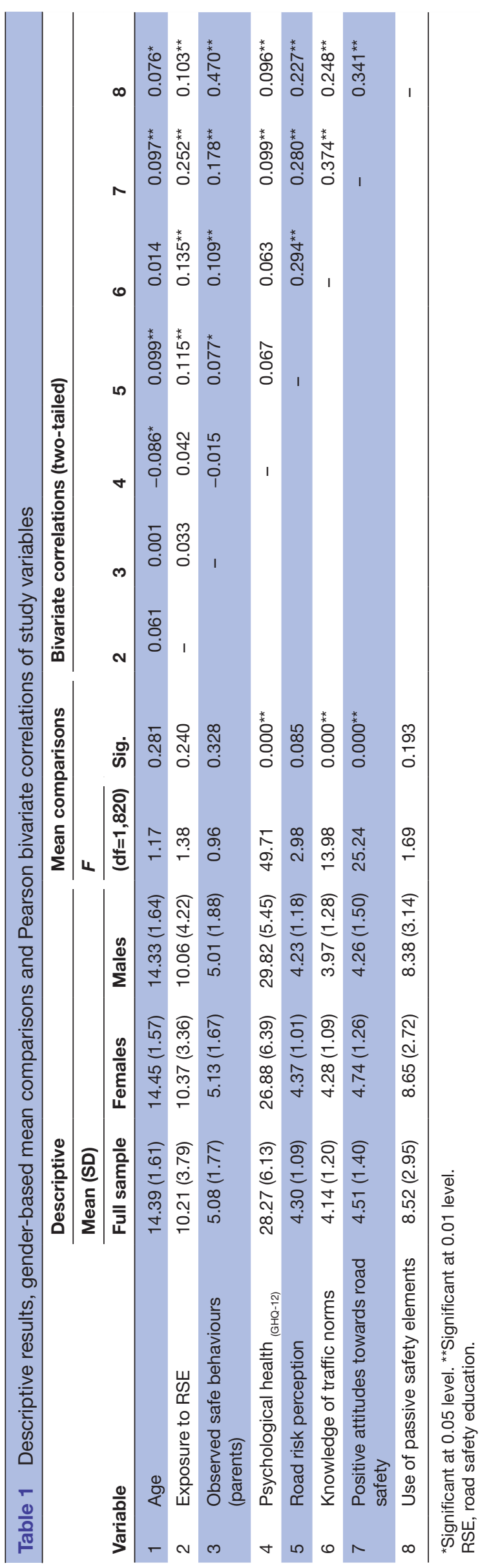


Table 2 Structural equation model (SEM) for predicting the use of PSEs (model A)

\begin{tabular}{|c|c|c|c|c|c|c|c|}
\hline SEM paths (full sample) & & & Std. estimate ${ }^{\dagger}$ & SE & CR & $P$ value & Sig. \\
\hline Positive attitudes & $\leftarrow$ & Observed safe behaviours & 0.172 & 0.026 & 5.214 & $<0.001$ & $* \star *$ \\
\hline Rule knowledge & $\leftarrow$ & Observed safe behaviours & 0.106 & 0.023 & 3.094 & 0.002 & ** \\
\hline Risk perception & $\leftarrow$ & Exposure to RSE & 0.104 & 0.010 & 3.027 & 0.002 & ** \\
\hline Risk perception & $\leftarrow$ & Observed safe behaviours & 0.075 & 0.021 & 2.181 & 0.029 & * \\
\hline Rule knowledge & $\leftarrow$ & Exposure to RSE & 0.129 & 0.011 & 3.753 & $<0.001$ & *** \\
\hline Positive attitudes & $\leftarrow$ & Exposure to RSE & 0.237 & 0.012 & 7.192 & $<0.001$ & $* \star *$ \\
\hline Risk perception & $\leftarrow$ & Age & 0.099 & 0.023 & 2.887 & 0.004 & ** \\
\hline Positive attitudes & $\leftarrow$ & Age & 0.091 & 0.029 & 2.763 & 0.006 & ** \\
\hline Rule knowledge & $\leftarrow$ & Age & 0.011 & 0.026 & 0.334 & 0.738 & $\mathrm{~N} / \mathrm{S}$ \\
\hline Positive attitudes & $\leftarrow$ & Psychological health & 0.100 & 0.008 & 3.023 & 0.003 & ** \\
\hline Rule knowledge & $\leftarrow$ & Psychological health & 0.060 & 0.007 & 1.748 & 0.080 & $\mathrm{~N} / \mathrm{S}$ \\
\hline Risk perception & $\leftarrow$ & Psychological health & 0.072 & 0.006 & 2.115 & 0.034 & * \\
\hline Use of passive safety elements & $\leftarrow$ & Age & 0.052 & 0.053 & 1.788 & 0.074 & $\mathrm{~N} / \mathrm{S}$ \\
\hline Use of passive safety elements & $\leftarrow$ & Exposure to RSE & 0.012 & 0.023 & 0.401 & 0.688 & $\mathrm{~N} / \mathrm{S}$ \\
\hline Use of passive safety elements & $\leftarrow$ & Observed safe behaviours & 0.420 & 0.048 & 14.377 & $<0.001$ & *** \\
\hline Use of passive safety elements & $\leftarrow$ & Risk perception & 0.103 & 0.083 & 3.365 & $<0.001$ & $\star \star \star *$ \\
\hline Use of passive safety elements & $\leftarrow$ & Rule knowledge & 0.095 & 0.078 & 2.992 & 0.003 & ** \\
\hline Use of passive safety elements & $\leftarrow$ & Positive attitudes & 0.186 & 0.069 & 5.686 & $<0.001$ & *** \\
\hline Use of passive safety elements & $\leftarrow$ & Psychological health & 0.075 & 0.014 & 2.586 & 0.010 & * \\
\hline
\end{tabular}

${ }^{* * *}$ Significant at level 0.001. ${ }^{* *}$ Significant at level 0.01. * Significant at level 0.05 .

†SPC, sandardised path coefficients (can be interpreted as linear regression weights).

$\mathrm{CR}$, critical ratio; RSE, road safety education.

was assessed using an MGSEM approach: this is extensively different from modelling gender groups within the variables included in the general structural model. In this sense, the data were split into two groups (Group 1: female; Group 2: male), presenting an acceptable sample size and optimal conditions for comparability. Using the

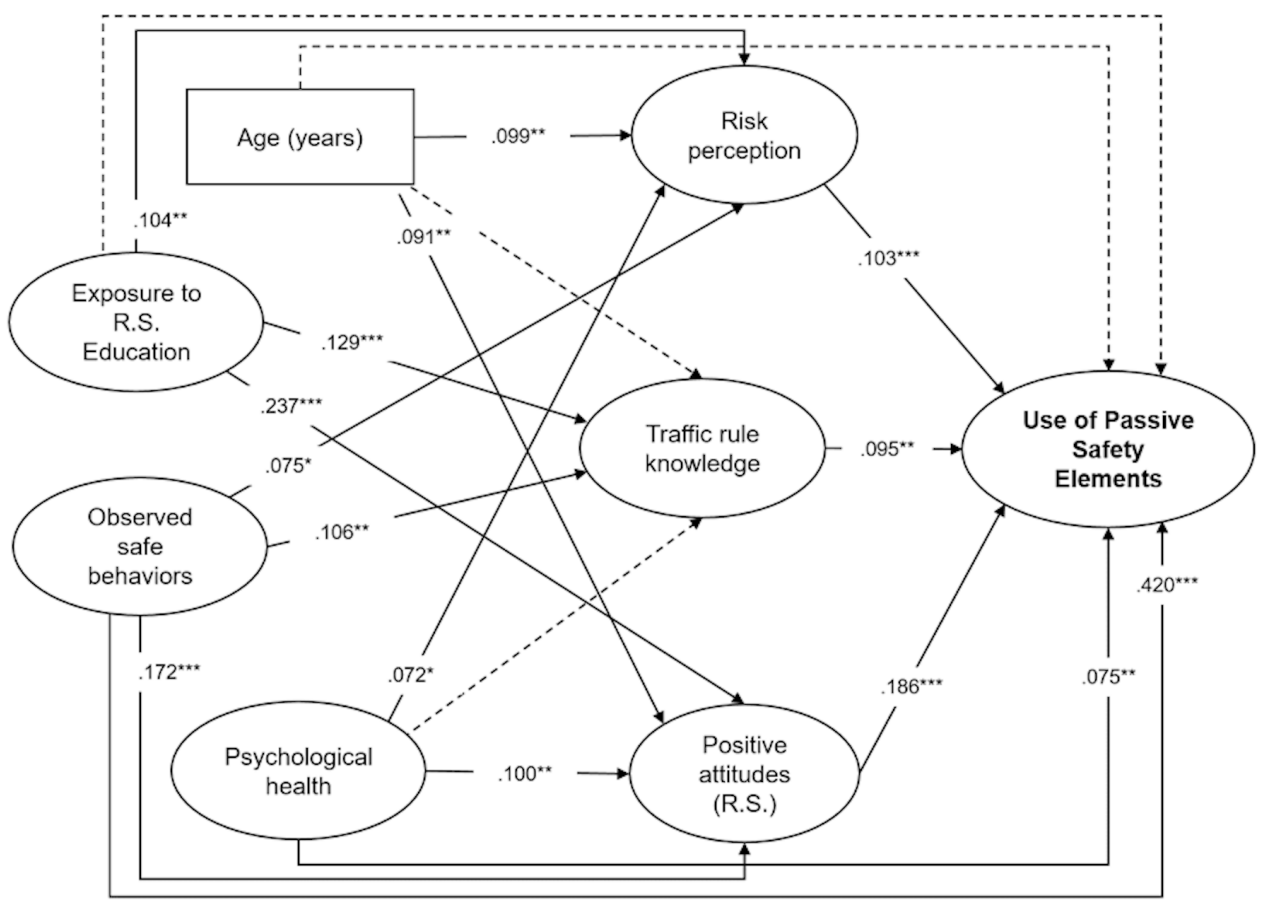

Figure 2 Graphic presentation of the structural equation model for predicting the use of PSEs. Solid lines represent significant paths. ${ }^{*} \mathrm{p}<0.05 ;{ }^{\star *} \mathrm{p}<0.01 ;{ }^{* \star *} \mathrm{p}<0.001$. PSE, passive safety education; RSE, road safety education. 
AMOS multigroup comparison analysis, the hypothesised structural model was adjusted following a multigroup invariance-testing strategy.

Same as Model A, the MGSEM model was specified in a sequence similar to the one recommended in expert literature. ${ }^{25}$ As baseline model did not optimally fit the data $\left(x^{2}(18)=190.05, \quad \mathrm{p}<0.001 ; \quad \mathrm{NFI}=0.727 ; \quad \mathrm{CFI}=0.732\right.$; RMSEA $=0.109 ; \quad \mathrm{CMIN} / \mathrm{DF}=10.559), \quad$ and therefore structural modifications were applied to constrain the model. The resulting SEM reported better fit coefficients $\left(x^{2}(18)=63.214, p<0.001 ; \mathrm{NFI}=0.909 ; \mathrm{CFI}=0.929\right.$; RMSEA=0.055; CMIN/DF=3.512), and it is presented in table 3 and figure 3 . In addition to the multigroup invariance test, indicating that the model works similarly well for both of them, the RMSEA $(<0.08)$, NFI/CFI $(>0.90)$ coefficients suggested an optimal fit for the final model, ${ }^{25-27}$ showing that factor loadings, intercepts and residual covariances, were operating equivalently in both groups.

\section{Gender differences and similarities}

The MGSEM model shows that, although both groups keep similar characteristics, there are some key structural gender differences in what concerns the differential effect of the study variables on the use of PSEs. First, and regarding the observed similarities, we see how (for both genders): exposure to RSE has a significant effect on rule knowledge $\left(\beta=0.159^{* * * *}\right.$ females; $\beta=0.104^{*}$ males $)$ and attitudes towards road safety $\left(\beta=0.227^{* * * *}\right.$ females; $\beta=0.230^{* * *-}$ males). Also, the observed safe behaviours significantly influence the positive attitudes of subjects towards road safety ( $\beta=0.167^{* * * *}$ females; $\beta=0.169^{* * * *}$ males) and the use of PSEs $\left(\beta=0.383^{* * * *}\right.$ females; $\beta=0.455^{* * * *}$ males). Furthermore, psychological health has an effect on positive attitudes towards road safety in both groups $\left(\beta=0.119^{* *}\right.$ females; $\beta=0.174^{* * * *}$ males $)$. Finally, risk perception $\left(\beta=0.121^{* * *} \mathrm{fe}-\right.$ males; $\beta=0.106^{*}$ males) and positive attitudes towards road safety ( $\beta=0.244^{* * * *}$ females; $\beta=0.138^{* *}$ males) has a similar and significant effect on the use of passive safety elements.

Second, and regarding gender differences, it was found that: unlike male teenagers, in the case of females age has a significant effect on risk perception $\left(\beta=0.131^{* * *}\right)$ and positive attitudes towards road safety $\left(\beta=0.150^{* * *}\right)$. Also, the exposure to RSE influence risk perception $\left(\beta=0.136^{* * * *}\right)$, and psychological health has a positive effect on the use of PSEs $\left(\beta=0.086^{*}\right)$. All these paths were non-statistically significant for male teenagers. On the other hand, there is a set of significant effects that were only observed in males: the safe behaviours observed in parents were linked to the knowledge of traffic rules $\left(\beta=0.204^{* * *}\right)$, and psychological health had a significant effect on both risk perception $\left(\beta=0.172^{* * * *}\right)$ and the traffic rule knowledge $\left(\beta=0.102^{*}\right)$, paths that were non-significant for females.

\section{DISCUSSION AND CONCLUSION}

The main objectives of this study were, first, to test the effects of sociodemographic variables, and the effects of three key road safety skills (knowledge-risk perception-attitudes) on the use of PSEs among teenagers; and second, to assess the differential impact of the study variables on PSEs use from a gender-based perspective.

Regarding the first objective of the study, the results of this study allowed us to establish that the use of such elements in teenagers is not only correlated, but also largely explained by several variables related to age, psychological health and RSE, through the mediation of road safety skills: risk perception, knowledge of traffic rules and positive attitudes towards road safety. In short, the directionality of the significant bivariate correlations between demographic variables, road safety skills and the use of PSEs suggests that these factors are associated between themselves; however, the predictive mechanism needed to be tested through a theoretically supported model, which in turn had to be tested in this population. In this regard, the SEM modelling was performed, and a parsimonious model with an adequate fit was obtained. In this Model $A$, built in accordance with the revised literature, it was interesting to observe how the directions and significance of the associations between study variables suggest the need for strengthening road safetyrelated skills as a way of improving safe behaviours, ${ }^{4}$ in accordance to what was already stated by other researches dealing with Spanish-speaking populations. ${ }^{48} 29$ Most of these conclusions support that systematic exposure to enough information/education in road safety settings is, perhaps, the most effective measure for minimising road risks and traffic injuries among teenagers. ${ }^{82}$

\section{'Similar, but different': a summary of gender similarities and disparities}

As for the second objective of the study, we found that, although several similarities can be observed across male and female teenagers, some key differences are noticeable. Accordingly, previous studies on road safety behaviour have shown that, even though great similarities and uniform patterns may be observed across genders, key differences in the role of demographic factors, mental health and educational aspects might explain differential outcomes in both risky and protective road behaviours of individuals. ${ }^{30-32}$ Also, several studies have already suggested that risky road behaviours can be more frequent and dangerous, and protective behaviours less prevalent in the case of male road users. ${ }^{18} 32$

Furthermore, local studies have stated that there is a gender disparity in the injury protection through PSEs ${ }^{33}$ of people, although differences in this regard have been reported as non-significant in some other studies performed on adult samples: ${ }^{3435}$ this implies a differential state-of-affairs based on factors such as the law enforcement and the road safety culture of each country. ${ }^{31}$ In this regard, it is worth mentioning that, although nonsignificant differences were found in the extent to which subjects of both genders use PSEs, the mean score was tendentially higher for females. Furthermore, significant mean differences were found in the case of two road 
Table 3 Gender-based multigroup (MGSEM) model for predicting the use of PSEs (Model B)

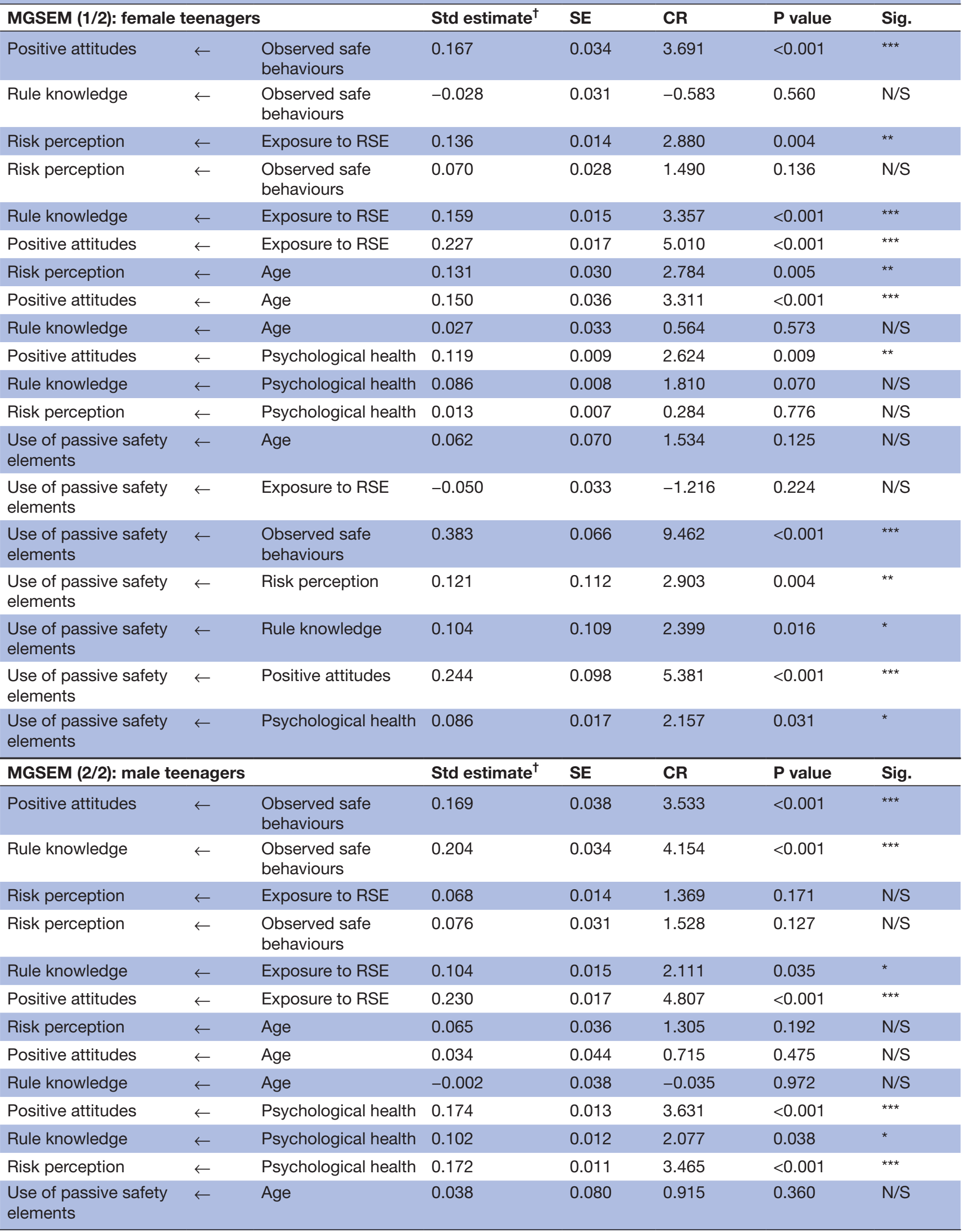




\begin{tabular}{|c|c|c|c|c|c|c|c|}
\hline \multicolumn{3}{|c|}{ MGSEM (2/2): male teenagers } & \multirow{2}{*}{$\begin{array}{l}\text { Std estimate }^{\dagger} \\
0.056\end{array}$} & \multirow{2}{*}{$\begin{array}{l}\text { SE } \\
0.032\end{array}$} & \multirow{2}{*}{$\begin{array}{l}\text { CR } \\
1.314\end{array}$} & \multirow{2}{*}{$\begin{array}{l}\text { P value } \\
0.189\end{array}$} & \multirow{2}{*}{$\begin{array}{l}\text { Sig } \\
\text { N/S }\end{array}$} \\
\hline $\begin{array}{l}\text { Use of passive safety } \\
\text { elements }\end{array}$ & $\leftarrow$ & Exposure to RSE & & & & & \\
\hline $\begin{array}{l}\text { Use of passive safety } \\
\text { elements }\end{array}$ & $\leftarrow$ & $\begin{array}{l}\text { Observed safe } \\
\text { behaviours }\end{array}$ & 0.455 & 0.072 & 1.618 & $<0.001$ & 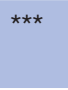 \\
\hline $\begin{array}{l}\text { Use of passive safety } \\
\text { elements }\end{array}$ & $\leftarrow$ & Rule knowledge & 0.076 & 0.115 & 1.614 & 0.106 & $\mathrm{~N} / \mathrm{S}$ \\
\hline $\begin{array}{l}\text { Use of passive safety } \\
\text { elements }\end{array}$ & $\leftarrow$ & Positive attitudes & 0.138 & 0.099 & 2.922 & 0.003 & $\star \star$ \\
\hline $\begin{array}{l}\text { Use of passive safety } \\
\text { elements }\end{array}$ & $\leftarrow$ & Psychological health & 0.058 & 0.025 & 1.369 & 0.171 & $\mathrm{~N} / \mathrm{S}$ \\
\hline
\end{tabular}

${ }^{* * *}$ Significant at level 0.001. ${ }^{* *}$ Significant at level 0.01. *Significant at level 0.05.

CR, critical ratio; PSE, passive safety element; RSE, road safety education; SPC, Standardized Path Coefficients (can be interpreted as linear regression weights).

safety skills: rule knowledge and positive attitudes towards road safety (both higher for females), while the only study variable significantly higher for males was psychological health. $^{21}$

Bearing in mind the second objective of our research study (ie, to evaluate the differential impact of the study variables on the use of PSEs from a gender-based perspective through MGSEM), while at the same time comparing the structural models presented in figure 3 with the hypothesised assumption that there are key structural similarities (but also differences) between males and females, we discovered an interesting set of outcomes. First of all, age has a significant effect on risk perception and positive attitudes in females, but, in the case of males, it does not have a significant effect on any of the dependent variables. Apart from the mere gender difference, it is attention-worthy how, from a gender-based perspective, age may play a critical role in the perception of road risk situations and the production of safer behaviours within the set of problematic road safety behaviours observed in female road users. ${ }^{46}$ Also, we found that exposure to RSE, both in males and females, had a significant effect on the knowledge of traffic norms and on positive attitudes; however, RSE exposure only influenced the road risk perception of females. Regarding the observed safe behaviours of parents, while showing an effect on positive attitudes and (directly) on the use of passive safety elements for both genders, it exerted a significant influence on the knowledge of traffic rules only in male teenagers. Another differential outcome was found for what concerns the psychological health indicator: speaking of similarities, it influenced positive attitudes in both genders. As for particularities, the GHQ-12 score had a direct effect on females' use of PSEs, and on males' risk perception and traffic rules' knowledge. In this regard, the evidence has suggested that mental health may have a differential role in health-compromising behaviours that are also related to traffic, especially in the case of young male subjects, whose competences in decision making concerning safety issues could be highly influenced by their mental health condition. ${ }^{23} 37$

Regarding road safety skills, it was found that risk perception and positive attitudes, although differentially affected by independent study variables, had a significant effect on the use of passive safety elements for both male and female teenagers. However, positive attitudes towards road safety remain significantly higher for females, as it has been seen in some other studies involving young road users. ${ }^{38}$ Finally, and although knowledge of traffic rules had a direct effect on the use of PSEs in female teenagers, it was not significant for males. This could be supported by the gender differences found in mean comparisons (shown in table 1), in which males tend to report a significantly lower knowledge of traffic rules than females; similar studies focusing on gender differences such as the ones performed by Yahia et $a l^{39}$ and Eiksund ${ }^{40}$ confirm this. In fact, it constitutes the only assessed road safety skill that reported a structural gender-based difference.

Even though the self-reported frequency of the use of passive safety elements was overall high among Spanish teenagers (with an average score of 8.52/12), the discussion is still open for the complementary factors that strengthen the use of protective elements. The first element to be highlighted is law enforcement, since it directly involves both parents and educational institutions. In this regard, the evidence has demonstrated that, in the case of motor-vehicle users, policies on primary enforcement laws (and unbelted driver/passengers are a sufficient reason for imposing a traffic fine) have positive effects on the use of PSEs in teenagers, ${ }^{41}$ especially considering that the use of PSEs is highly enhanced by institutional stakeholders. Also, other studies $^{42}$ have prospectively demonstrated that the use of PSEs is significantly increased by law improvements. 

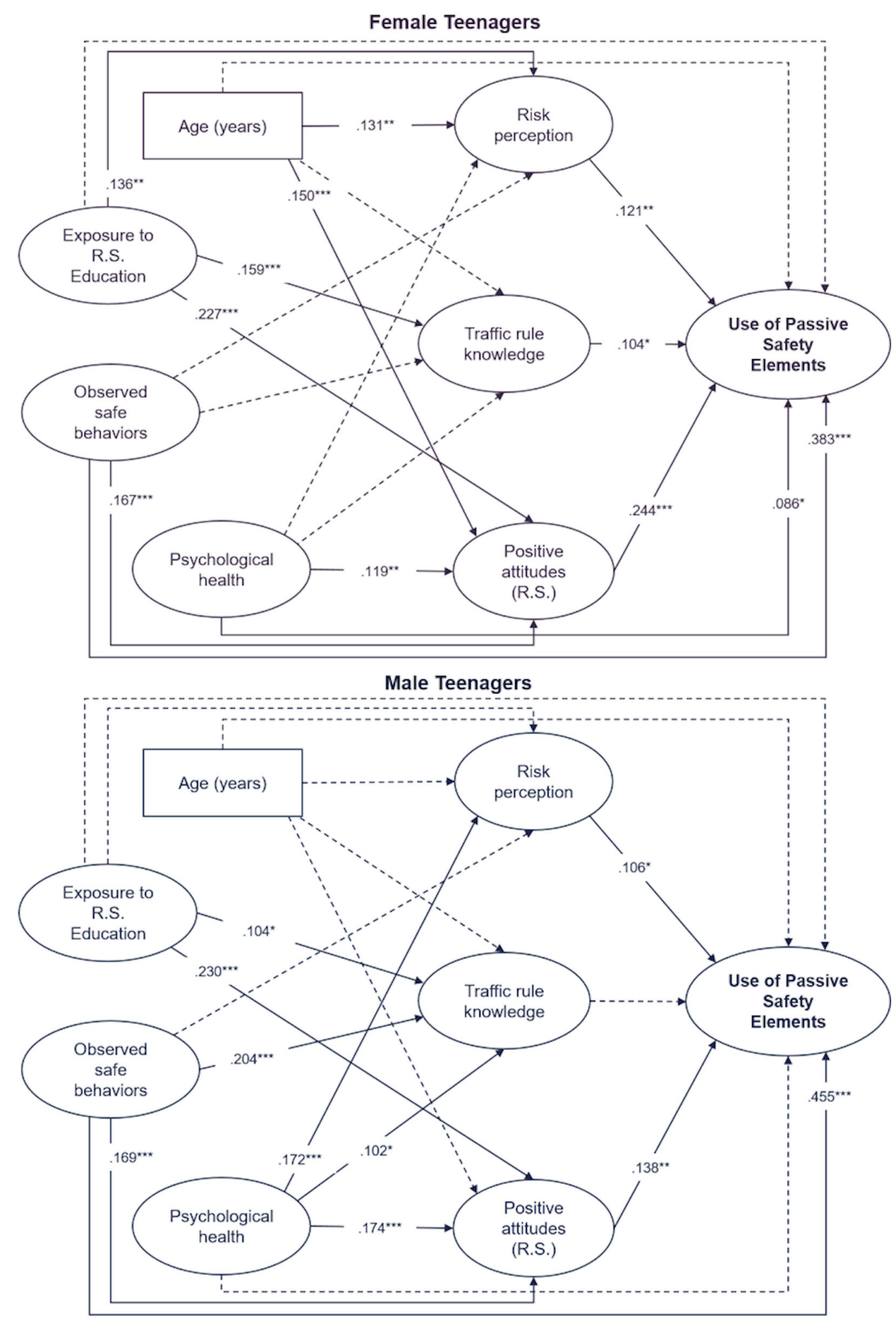

Figure 3 Two-group (MGSEM) structural model showing standardised path coefficients and significant paths (solid lines). Categories: females (above) and males (below). ${ }^{*} \mathrm{p}<0.05 ;{ }^{* \star} \mathrm{p}<0.01 ;{ }^{* \star *} \mathrm{p}<0.001$.

The second point to be highlighted is the parental influence on the safe habits of young road users. As it has been previously addressed, ${ }^{3} 743$ the implications of strengthening the parent-child relationship in the field of road safety carry an undisputable practical implication for the outcomes of our research. In fact, the results have both shown that the observed safe behaviours have an effect on the use of PSEs and also that they influence the positive attitudes of teenagers towards road safety and, in the particular case of males, towards the learning of traffic norms by means of the behaviours observed in parents and relatives. ${ }^{434}$

The third point that needs to be highlighted is the role of RSE. Studies suggest that with an increased set of skills, such as the knowledge of traffic norms (that might also be enforced by policymakers), road risk perception and favourable attitudes, it is possible to predict the safe road behaviours of people and, consequently, to foster fewer 
injuries derived from traffic crashes. ${ }^{28} 29$ Other studies have highlighted that increasing the use of PSEs is an urgent need for road safety, ${ }^{148}$ and the increase of RSE, especially during early life stages, is of key importance for developing both the present and future safe behaviours of children and adolescents.

Finally, it is worth mentioning the importance of the multilevel efforts made in the enforcement of both RSE and the available human and structural resources, with the aim of guaranteeing injury prevention among teenagers: more than 30 years ago, Spital, Spital and Spital ${ }^{19}$ claimed for a superior professional involvement (especially by part of physician paediatricians), in order to optimise the quality standards of passive safety in school transportation; furthermore, they advocated for the presence of more education within the community. Nowadays, it is worth highlighting that, as of yet developed countries have successfully policed minimum standards and guidelines in this regard while developing ones are 'on their way'-and this, up until now, has already saved many lives-yet it is not enough, since the ultimate objective is zero lives lost. This type of task has acquired a multidisciplinary approach ${ }^{45}$ which is currently and predominantly framed within the RSE approach, a fact that maximises the articulation and potentiality of multilevel researches, interventions and policies aimed at filling out pending issues in community health.

\section{Limitations of the study and further research}

Although basic methodological considerations were formulated, and core statistical parameters needed for the analyses were satisfactorily tested, some issues should be listed as potential biasing sources. First, this was a selfreport-based study, and it was therefore prone to present the common method bias, that may influence the results derived from the answers provided by the participants, especially when gathering information on issues that may be sensitive for them. ${ }^{46}$ This entails the need of being cautious when interpreting behavioural models based on self-reports. ${ }^{47}$ Also, topics related to the participants' behaviour may elicit social desirability: for this reason, we actively emphasised on the anonymity of the survey. Also, 23 incomplete data (not fully completed surveys) and acquiescent questionnaires (whose responses presented an atypical unilateral trend) were excluded during the data processing. Finally, although different standards exist in the educational system and the instruments were previously tested during a pilot phase, some additional assistance from the researcher was required by specific participants. This supports the need of having staff members being physically present during surveying, in order to clarify doubts and strengthen the correct completion of self-report-based questionnaires.

Furthermore, regarding the obtained bivariate correlations (oscillating between 0.076 and 0.248 ), it is worth saying that, although procedural parameters were followed during the data analysis, some relatively small correlations were found. This could be related to the effect of having a large sample size that might lead to the finding of significant variable associations, even when their relationship could be very small or moderate. In other words, huge sample sizes can amplify the bias associated with inferential errors, reason why it is important to be cautious with this kind of sample size-related issues. ${ }^{48-50}$

This study offers useful information for researchers, practitioners and policymakers on factors that strengthen the use of PSEs among adolescents and, thus, can decrease their injury risk in traffic crashes. These evidence-based findings could be addressed in interventions and multisectoral strategies aimed at improving the road safety competences of young population.

Acknowledgements The authors would like to thank the different centers involved in this study and the staff (directors, section coordinators and professors), since they were crucial for the collection of the data. Also, thanks to Runa Falzolgher for the professional edition of the original manuscript, and to Iván Méndez for the professional reading proof of the revised paper.

Collaborators Cristina Esteban.

Contributors For this study, SU conceived and designed the research; SU and LG performed the data collection; SU and FA analysed the data; FA contributed reagents/materials/analysis tools; SU and LM wrote and revised the paper.

Funding The authors have not declared a specific grant for this research from any funding agency in the public, commercial or not-for-profit sectors.

Competing interests None declared.

Patient consent for publication Not required.

Ethics approval To perform this study, the Committee of Ethics in Social Science in Health Research of the University of Valencia was consulted, certifying that it responded to the ethical principles and that it complied with the Declaration of Helsinki, thus granting it a positive guesstimate (IRB approval number H1535548125595).

Provenance and peer review Not commissioned; externally peer reviewed.

Data availability statement Data are available upon reasonable request.

Open access This is an open access article distributed in accordance with the Creative Commons Attribution Non Commercial (CC BY-NC 4.0) license, which permits others to distribute, remix, adapt, build upon this work non-commercially, and license their derivative works on different terms, provided the original work is properly cited, appropriate credit is given, any changes made indicated, and the use is non-commercial. See: http://creativecommons.org/licenses/by-nc/4.0/.

ORCID iD

Sergio Useche http://orcid.org/0000-0002-5099-4627

\section{REFERENCES}

1 Secginli S, Cosansu G, Nahcivan NO. Factors associated with bicycle-helmet use among 8-16 years aged Turkish children: a questionnaire survey. Int J Inj Contr Saf Promot 2014;21:367-75.

2 Ross TP, Ross LT, Rahman A, et al. The bicycle helmet attitudes scale: using the health belief model to predict helmet use among undergraduates. J Am Coll Health 2010;59:29-36.

3 Habib RR, Hamdan M, Al-Sahab B, et al. The influence of parentchild relationship on safety belt use among school children in Beirut. Health Promot Int 2010;25:403-11.

4 Alonso F, Esteban C, Useche S, et al. Effect of road safety education on road risky behaviors of Spanish children and adolescents: findings from a national study. Int J Environ Res Public Health 2018;15:2828.

5 Baker S, Morawska A, Mitchell A. Promoting children's healthy habits through self-regulation via parenting. Clin Child Fam Psychol Rev 2019;22:52-62.

6 Curry AE, Peek-Asa C, Hamann CJ, et al. Effectiveness of ParentFocused interventions to increase teen driver safety: a critical review. $\checkmark$ Adolesc Health 2015;57:S6-14. 
7 Simons-Morton BG, Ouimet MC, Catalano RF. Parenting and the young driver problem. Am J Prev Med 2008;35:S294-303.

8 Shults RA, Haegerich TM, Bhat G, et al. Teens and seat belt use: what makes them click? J Safety Res 2016;57:19-25.

9 Briggs NC, Lambert EW, Goldzweig IA, et al. Driver and passenger seatbelt use among U.S. high school students. Am J Prev Med 2008;35:224-9.

10 Heng KWJ, Lee AHP, Zhu S, et al. Helmet use and bicycle-related trauma in patients presenting to an acute hospital in Singapore. Singapore Med J 2006;47:367-72.

11 Chong S-L, Tyebally A, Chew SY, et al. Road traffic injuries among children and adolescents in Singapore - Who is at greatest risk? Accid Anal Prev 2017;100:59-64.

12 Finnoff JT, Laskowski ER, Altman KL, et al. Barriers to bicycle helmet use. Pediatrics 2001;108:E4.

13 Taylor P. The STATs behind the bicycle helmet, 2016. Available: https://bicycleuniverse.com/stats-behind-bicycle-helmet/

14 Thrasybule L. Helmets prevent severe head injuries in bike accidents. web resource, 2016. Available: https://www.reuters.com/article/ us-health-bicycles-helmets/helmets-prevent-severe-head-injuries-inbike-accidents-idUSKCN10U1LY

15 Useche SA, Montoro L, Sanmartin J, et al. Healthy but risky: A descriptive study on cyclists' encouraging and discouraging factors for using bicycles, habits and safety outcomes. Transportation Research Part F 2019;62:587-98.

16 Pickett W, Molcho M, Simpson K, et al. Cross national study of injury and social determinants in adolescents. Inj Prev 2005;11:213-8.

17 Durkin MS, Laraque D, Lubman I, et al. Epidemiology and prevention of traffic injuries to urban children and adolescents. Pediatrics 1999;103:e74.

18 Beck LF, Shults RA, Mack KA, et al. Associations between sociodemographics and safety belt use in states with and without primary enforcement laws. Am J Public Health 2007;97:1619-24.

19 Spital M, Spital A, Spital R. The compelling case for seat belts on school buses. Pediatrics 1986;78:928-32.

20 Demetriou C, Uzun B, Essau CA. Self-Report Questionnaires. In: Cautin RL, Lilienfeld SO, eds. The encyclopedia of clinical psychology. New Jersey: John Wiley \& Sons, 2015: 1-4.

21 Goldberg D, Questionnaire GH. General health questionnaire (GHQ12. Windsor: NFER-Nelson, 1992.

22 Urzúa A, Caqueo-Urízar A, Bargsted M, et al. [Does the GHQ-12 scoring system affect its factor structure? An exploratory study of Ibero American students]. Cad Saude Publica 2015;31:1305-12.

23 Padrón A. Risk Factors of Psychological Distress in Adolescent Population, Assessed Through the General Health Questionnaire (GHQ-12) [Doctoral Thesis]. Madrid, Universidad Autónoma de Madrid, 2012.

24 MacKinnon D, Cheong JW, Pirlott AG. An Introduction to Statistical Mediation Analysis. In: Cooper H, Camic PM, Long DL, eds. Apa Handbook of research methods in psychology, vol 2: research designs: quantitative, qualitative, neuropsychological, and biological. Washington, DC, US: American Psychological Association, 2012.

25 Marsh HW, Hau K-T, Wen Z. In search of golden rules: Comment on Hypothesis-Testing approaches to setting cutoff values for fit indexes and dangers in Overgeneralizing HU and Bentler's (1999) findings. Structural Equation Model 2004;11:320-41.

26 Yuan $\mathrm{K}-\mathrm{H}$, Chan W. Measurement invariance via multigroup SEM: issues and solutions with chi-square-difference tests. Psychol Methods 2016;21:405-26.

27 LT H, Bentler P. Cutoff criteria for fit indexes in covariance structure analysis: conventional criteria versus new alternatives. Struct Equ Model 1999;6:1-55.

28 Treviño-Siller S, Pacheco-Magaña LE, Bonilla-Fernández P, et al. An educational intervention in road safety among children and teenagers in Mexico. Traffic Inj Prev 2017;18:164-70.
29 Babio GO, Daponte-Codina A. Factors associated with seatbelt, helmet, and child safety seat use in a Spanish high-risk injury area. $J$ Trauma 2006;60:620-6.

30 Ghaffari M, Armoon B, Rakhshanderou S, et al. Determinants of seat belt use behaviour: a protocol for a systematic review. BMJ Open 2018;8:e020348.

31 Useche SA, Montoro L, Alonso F, et al. Does gender really matter? a structural equation model to explain risky and positive cycling behaviors. Accid Anal Prev 2018;118:86-95.

32 Barr GC, Kane KE, Barraco RD, et al. Gender differences in perceptions and self-reported driving behaviors among teenagers. $J$ Emerg Med 2015;48:366-70.

33 Bose D, Segui-Gomez M, Crandall JR. Vulnerability of female drivers involved in motor vehicle crashes: an analysis of US population at risk. Am J Public Health 2011;101:2368-73.

34 Mahfoud ZR, Cheema S, Alrouh H, et al. Seat belt and mobile phone use among vehicle drivers in the city of Doha, Qatar: an observational study. BMC Public Health 2015;15:937.

35 Zambon F, Fedeli U, Marchesan M, et al. Seat belt use among rear passengers: validity of self-reported versus observational measures. BMC Public Health 2008:8:233.

36 Glendon Al, Dorn L, Davies DR, et al. Age and gender differences in perceived accident likelihood and driver competences. Risk Anal 1996;16:755-62.

37 McDonald CC, Sommers MS, Fargo JD. Risky driving, mental health, and health-compromising behaviours: risk clustering in late adolescents and adults. Inj Prev 2014;20:365-72.

38 Cordellieri P, Baralla F, Ferlazzo F, et al. Gender effects in young road users on road safety attitudes, behaviors and risk perception. Front Psychol 2016;7:1412.

39 A.M. Yahia H, Ismail A, Ismael Albrka S, et al. Attitudes and awareness of traffic safety among drivers in Tripoli-Libya. RJASET 2014;7:5297-303.

40 Eiksund S. A geographical perspective on driving attitudes and behaviour among young adults in urban and rural Norway. Saf Sci 2009;47:529-36.

41 Durbin DR, Smith R, Kallan MJ, et al. Seat belt use among 13-15 year olds in primary and secondary enforcement law states. Accid Anal Prev 2007;39:524-9.

42 Parkin PC, Khambalia A, Kmet L, et al. Influence of socioeconomic status on the effectiveness of bicycle helmet legislation for children: a prospective observational study. Pediatrics 2003;112:e192-6.

43 Ginsburg KR, Durbin DR, García-España JF, et al. Associations between parenting styles and teen driving, safety-related behaviors and attitudes. Pediatrics 2009;124:1040-51.

44 Klein KS, Thompson D, Scheidt PC, et al. Factors associated with bicycle helmet use among young adolescents in a multinational sample. Inj Prev 2005;11:288-93.

45 Dellinger AM, West BA. Health care providers and teen driving safety: topics Discussed and educational resources used in practice. $A m \mathrm{~J}$ Lifestyle Med 2015;9:451-6.

46 Wingate S, Sng E, Loprinzi PD. The influence of common method bias on the relationship of the socio-ecological model in predicting physical activity behavior. Health Promot Perspect 2018;8:41-5.

47 Petróczi A, Nepusz T. Methodological considerations regarding response bias effect in substance use research: is correlation between the measured variables sufficient? Subst Abuse Treat Prev Policy 2011;6:1.

48 Kaplan RM, Chambers DA, Glasgow RE. Big data and large sample size: a cautionary note on the potential for bias. Clin Trans/ Sci 2014;7:342-6.

49 Goodwin LD, Leech NL. Understanding Correlation: Factors That Affect the Size of $r$. J Experiment Edu 2006;74:249-66.

50 Oviedo-Trespalacios O, Scott-Parker B. Young drivers and their cars: safe and sound or the perfect storm? Accid Anal Prev 2018;110:18-28. 